\title{
Differential Response of the Microbiome of Pocillopora acuta to Reciprocal Transplantation Within Singapore
}

\author{
Lindsey K. Deignan ${ }^{1} \cdot$ Diane McDougald ${ }^{1,2}$
}

Received: 24 January 2021 / Accepted: 10 June 2021 / Published online: 19 June 2021

(c) The Author(s) 2021

\begin{abstract}
As corals continue to decline globally, particularly due to climate change, it is vital to understand the extent to which their microbiome may confer an adaptive resilience against environmental stress. Corals that survive on the urban reefs of Singapore are ideal candidates to study the association of scleractinians with their microbiome, which in turn can inform reef conservation and management. In this study, we monitored differences in the microbiome of Pocillopora acuta colonies reciprocally transplanted between two reefs, Raffles and Kusu, within the Port of Singapore, where corals face intense anthropogenic impacts. Pocillopora acuta had previously been shown to host distinct microbial communities between these two reefs. Amplicon sequencing (16S rRNA) was used to assess the coral microbiomes at 1, 2, 4, and 10 days post-transplantation. Coral microbiomes responded rapidly to transplantation, becoming similar to those of the local corals at the destination reef within one day at Raffles and within two days at Kusu. Elevated nitrate concentrations were detected at Raffles for the duration of the study, potentially influencing the microbiome's response to transplantation. The persistence of corals within the port of Singapore highlights the ability of corals to adapt to stressful environments. Further, coral resilience appears to coincide with a dynamic microbiome which can undergo shifts in composition without succumbing to dysbiosis.
\end{abstract}

Keywords Urban reef $\cdot$ Coral resilience $\cdot$ Coral microbiology $\cdot$ Coral microbiome

\section{Introduction}

Scleractinian corals are the building blocks of ecologically and economically valuable reef ecosystems, yet corals are experiencing ongoing global declines $[1,2]$. Coral survival depends on the maintenance of the coral host with its microbial symbionts, the coral holobiont [3]. Corals harbor photosynthetic endosymbiotic dinoflagellates (Symbiodiniaceae), which support coral growth through a well-described relationship $[4,5]$. Additionally, corals host a diverse microbial community, or microbiome, that plays essential roles in healthy coral functions, including nutrient cycling and immune responses $[3,6]$. However, the specific breakdown in functional roles of the microbiome members is not fully

Lindsey K. Deignan

Ldeignan@ntu.edu.sg

1 Singapore Centre for Environmental Life Sciences Engineering, Nanyang Technological University, 60 Nanyang Drive, SBS-01N-27, Singapore 637551, Singapore

2 The iThree Institute, University of Technology Sydney, Sydney, NSW 2007, Australia understood. The beneficial properties of the microbiome are likely to be contributed by a relatively small group of conserved core microbiome members and a larger group of transient members [7, 8]. Recently, increased research effort has been devoted to better understanding the potential of the microbiome to enable the coral host to withstand environmental perturbations $[9,10]$.

While coral microbiomes are generally comprised of species-specific communities [11, 12], environmental perturbations like nutrient or temperature fluxes can induce compositional shifts that vary both spatially [13] and temporally [14-17]. It has been proposed that coral species that maintain stable microbiomes may be more tolerant to environmental stressors [18, 19]. For example, the coral Porites lobata maintained a stable microbiome during a bleaching event, which supported some protective functions in the host despite the adverse physiological effects of bleaching [20]. However, Pogoreutz et al. [21] found that the stability of the microbiome of Pocillopora verrucosa following nutrient enrichment was unable to prevent bleaching or mortality. More frequently, coral microbiome beta diversity is reported to increase with cumulative environmental stressors [16, 17, 
22-24], suggesting that a shift in microbiome diversity is needed to counter the effects of long-term stress exposure. Alternatively, it may suggest that the coral lacks the ability to maintain a stable microbial community following perturbation.

Because the coral microbiome appears to contribute to protection of the host during stress, it has been hypothesized that microbiome manipulation, through the inoculation of the coral with presumptively beneficial bacteria, could represent a strategy to enhance coral resilience $[9,10]$. However, the functional role of microbial species in maintaining homeostasis in the coral holobiont and the specificity of the microbiome to the local environment are not fully understood. Singaporean corals have adapted to survive intense anthropogenic impacts [25-28], yet the extent to which the coral microbiome contributes to resilience in Singaporean corals remains unclear.

This study focuses on Pocillopora acuta, a particularly resilient coral species found in relatively high abundance on reefs throughout Singapore's Southern Islands [25, 29]. Previous studies have established that $P$. acuta located at Pulau Satumu (also referred to as Raffles Lighthouse) and Kusu Island, two of Singapore's Southern Islands separated by approximately $15 \mathrm{~km}$, harbor distinct microbial communities, despite their spatial proximities $[13,30]$. The waters around the Southern Islands are thought to be well-mixed, but Kusu is located closer to the Singapore mainland and is therefore potentially more exposed to anthropogenic impacts [31]. In this study, we assessed microbiome differences between reefs by monitoring $P$. acuta microbiome following a reciprocal transplantation, as a means of elucidating the microbiome dynamics of corals adapted to environmentally stressful urban reefs.

\section{Materials and Methods}

\section{Transplantation Experiment}

Six colonies of $P$. acuta separated by at least $5 \mathrm{~m}$ were selected at random from both Raffles lighthouse (Raffles; $1^{\circ} 09^{\prime} 39^{\prime \prime} \mathrm{N}, 103^{\circ} 44^{\prime} 26^{\prime \prime} \mathrm{E}$ ) and Kusu Island (Kusu; $1^{\circ} 13^{\prime} 32^{\prime \prime} \mathrm{N}, 103^{\circ} 51^{\prime} 35^{\prime \prime} \mathrm{E}$; Fig. S1). From each colony, nine 8-10-cm branches were fragmented (all colonies were large enough such that a maximum of one quarter of the colony was fragmented). Two cable ties were used to secure each fragment base to a PVC frame that was mounted approximately $25 \mathrm{~cm}$ above the reef benthos (Fig. S2). Following a 72-h acclimation period, one fragment from each colony was sampled representing a day 0 control; after which, four fragments from each colony were transplanted to their reciprocal reef, either transplanted from Raffles to Kusu (Transplant RK) or from Kusu to Raffles (Transplant KR).
The remaining four fragments from each colony remained at their resident reef, Resident Raffles and Resident Kusu. One fragment from each colony was sampled at each reef at days $1,2,4$, and 10 post-transplantation. All collected fragments were immediately placed in a dryshipper for transport to a $-80{ }^{\circ} \mathrm{C}$ freezer for storage. Coral tissue was collected from each fragment by blasting with compressed air, avoiding the base of the fragment directly under where the cable ties had been fastened. Additionally, on each sampling day, 1-L seawater samples were collected at each reef within $1 \mathrm{~m}$ of the transplant frames and placed on ice for transport to the laboratory for filtration through a $0.2-\mu$ f filter. All filters were immediately stored at $-80^{\circ} \mathrm{C}$. While in the field, $10 \mathrm{ml}$ of $0.2 \mu \mathrm{l}$ filtered seawater was collected in an acid cleaned falcon tube and immediately stored in a dryshipper for nutrient analysis on an AA3 AutoAnalyzer at the Asian School of the Environment at Nanyang Technological University. Hobo temperature loggers were deployed on each reef to record daily temperatures for the duration of the experimental period.

\section{DNA Extraction and Sequencing}

DNA extraction from the coral tissue and seawater filters was conducted using the Qiagen DNeasy PowerBiofilm kit, followed by the Zymo Clean-up and Concentrator kit. Extracted DNA was stored at $-20{ }^{\circ} \mathrm{C}$. PCR was performed with $10 \mu \mathrm{l}$ HotStarTaq Plus Master Mix, $1 \mu \mathrm{l}$ each of $10 \mu \mathrm{M}$ forward and reverse primers, $4 \mu \mathrm{l}$ water, $1 \mu \mathrm{l} 100 \%$ dimethyl sulfoxide (DMSO), $1 \mu \mathrm{l}$ of $200 \mathrm{ng} / \mu \mathrm{l}$ bovine serum albumin (BSA), and $2 \mu \mathrm{l}$ template DNA $(5 \mathrm{ng} / \mu \mathrm{l})$. The $515 \mathrm{~F}$ and 806R primers were used to amplify the $\mathrm{V} 4$ region of the $16 \mathrm{~S}$ rRNA gene to target the prokaryotic community members of the coral microbiomes [32]. Triplicate PCR reactions were run using the following conditions: an initial denaturation at $95{ }^{\circ} \mathrm{C}$ for $5 \mathrm{~min}$, followed by 37 cycles of $94{ }^{\circ} \mathrm{C}$ for $30 \mathrm{~s}$, $53{ }^{\circ} \mathrm{C}$ for $40 \mathrm{~s}$, and $72{ }^{\circ} \mathrm{C}$ for $1 \mathrm{~min}$, and a final extension of $10 \mathrm{~min}$ at $72{ }^{\circ} \mathrm{C}$. Triplicate samples were pooled for gel extraction. Three blank controls were subjected to identical DNA extraction, amplification, and clean-up methods. All samples were quantified using a Qubit 2.0 fluorometer and quality checked on an Agilent 2200 TapeStation before transferring to the Singapore Centre for Environmental Life Sciences Engineering, Nanyang Technological University, for library preparation and amplicon sequencing on an Illumina MiSeq platform. Raw sequencing reads were uploaded to the NCBI Sequence Read Archive (SRA) under BioProject PRJNA667314.

Amplicon sequencing data were processed using Dada2 version 1.16 to generate amplicon sequence variants (ASVs) for each sample replicate. Briefly, paired sequence reads were trimmed to 200 for the forward read and 170 for the reverse read and then filtered with an expected error rate of 
2. Error learning algorithms were applied to the forward and reverse reads before reads were merged, and chimeric sequences were removed. Contaminating sequence reads based on comparison with blank extractions were removed using the decontam package [33]. Taxonomy was assigned to the genus level using the IDTAXA algorithm from the $\mathrm{R}$ package DECIPHER v 2.16.1 based on the SILVA SSU r138 database [34]. Sequences identified as mitochondria, chloroplast, or unassigned to a Domain were removed. Due to situational limitations, a portion of the laboratory sample processing was conducted from July to November 2019, and the remaining sample processing was conducted from March to July 2020. As an additional control measure, Dirichlet Multinomial Mixtures (DMM) models of the day 0 control samples and resident colonies from Kusu and Raffles were used to confirm the removal of sample processor bias based on the temporal separation of sample processing using the DirichletMultinomial package in R [35]. DMM models were restricted to ASVs with $>0.1 \%$ relative abundance in $50 \%$ of the samples to target contamination that would be present at an abundance with the potential to bias results, without accounting for the lower abundant ASVs that contribute to the site differences between Raffles and Kusu. The models were run for up to 6 potential Dirichlet mixture components, and a Laplace model was used to test goodness of fit [36]. Initial DMM models performed on the sequencing data grouped the samples into 2 Dirichlet mixture components, or clusters, which matched directly to processing year (Fig. S3). Four ASVs were found to correlate directly to processing year; two Pseudomonas spp. were only present in the samples processed in 2019 , and two Ralstonia spp. were only present in high abundance in the samples processed in 2020. Due to the direct correlation of these ASVs with processing year, they were removed as contaminants. Confirmation of these ASVs as contaminants and not contributing to experimental results was verified with follow-up DMM models, which grouped the coral samples into one Dirichlet mixture component following removal of the 4 ASVs (Fig. S4). Finally, rarefaction curves were used to assess samples which reached their ASV maximum, and five samples were removed for failing to meet asymptotic levels (Fig. S5). The remaining samples were rarefied to 8416 sequence reads per sample to account for variation in sequencing depths for the calculation of diversity metrics [37]. The code used to generate the final dataset is available at https://github.com/LindseyKDeignan/Pocillopora_trans plantation.

\section{Data Analysis}

To examine the patterns of coral-associated prokaryotic communities, non-metric multidimensional scaling (nMDS) plots were created using Bray-Curtis similarity matrices of square root transformed data with the Vegan package in $\mathrm{R} v 3$.4.3. Permutational multivariate analyses of variance (PERMANOVA) were performed using the PERMANOVA + add-on in PRIMER 7 to compare between coral fragment origin and location over time. Analyses of location were used to compare the resident fragments and the fragments transplanted to that location with those on the opposite reef (Resident Raffles and Transplant KR vs. Resident Kusu and Transplant RK). Analyses of origin were performed to compare the resident fragments and the fragments transplanted away from that location to the fragments that originated from the opposite reef (Resident Raffles and Transplant RK vs. Resident Kusu and Transplant KR). Permutational multivariate analysis of dispersion (PERMDISP) was used to test for homogeneity of dispersion among samples within groups. The PERMDISP analysis can also be used as a measure of beta diversity between sample groups [23]. Multiple pairwise comparisons were corrected based on the Benjamini and Yekutieli (B-Y) false discovery rate control [38].

To determine the specific ASVs that contributed to the differences detected by PERMANOVA, multivariate generalized linear models (GLMs) with negative binomial distribution were performed in $\mathrm{R} \vee 3.4 .3$ using the mvabund package. Each dataset was subsampled to 500 OTUs for the GLM analysis. These analytical methods were first used to establish a difference in the prokaryotic communities of the coral microbiomes between the two reef sites and then among resident coral microbiomes within each site individually over the 10-day experimental period. The GLMs were also used to compare the resident coral microbiomes to those of the transplanted coral fragments where differences were detected with PERMANOVA.

\section{Results}

Coral fragments remained visually healthy at both sites for the duration of the experiment, with few exceptions. Corals originating from Raffles maintained a slightly lighter coloration, without bleaching, throughout the experiment as compared to fragments originating from Kusu. Four Resident Kusu fragments died. Among the transplanted colonies, 1 Transplant RK and 2 Transplant KR were dead by day 10 . Death of a fragment was defined as $>80 \%$ tissue loss. Of the surviving fragments, 8 failed to meet sequencing criteria and were excluded from the analysis, resulting in 92 total fragments analyzed (Table S1).

Coral microbiomes of the Resident Raffles samples were significantly different from the Resident Kusu samples (PERMANOVA, pseudo- $\mathrm{F}=2.0566, \mathrm{P}=0.001$; Fig. 1). Coral samples were distinct from seawater samples (PERMANOVA, pseudo- $\mathrm{F}=11.262 ; \mathrm{P}=0.001$ ), while seawater 
Fig. 1 nMDS plot of all Seawater and Resident Raffles and Kusu samples for all sampling time points of the transplantation experiment graphically represented as a spider plot connecting each sample with the group centroid

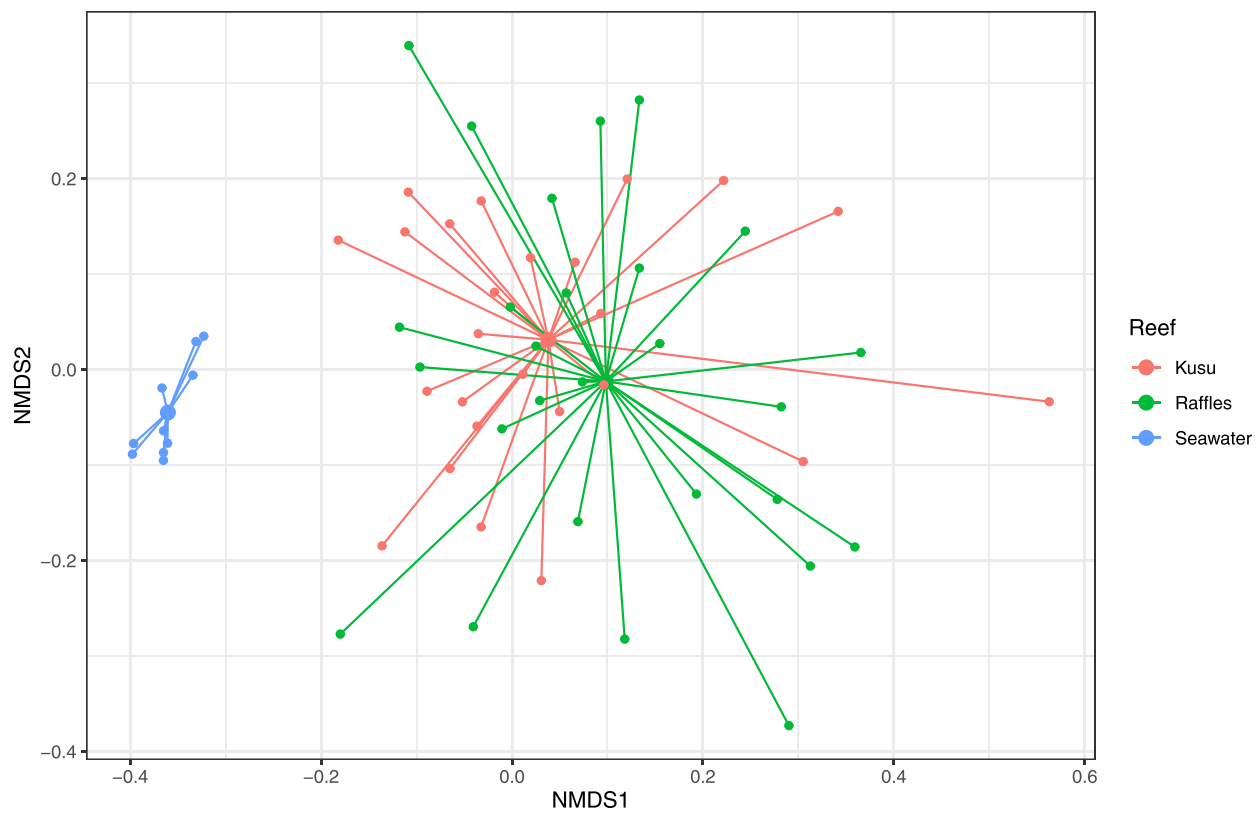

samples from each reef were not significantly different (PERMANOVA, pseudo- $\mathrm{F}=1.5053 ; \mathrm{P}=0.145$ ). The microbiomes of coral fragments at all time points were dominated by Proteobacteria, followed by Cyanobacteria (Fig. 2). At Raffles, there was a higher relative abundance of Proteobacteria for both the Resident and Transplanted fragments, while at Kusu, the Resident and Transplanted fragments had a relatively higher abundance of Cyanobacteria. The Cyanobacteria were composed almost exclusively of Cyanobacteriaceae, while the Proteobacteria were represented by high proportions of Rhodobacteraceae and unclassified families (Fig. 3). Alpha diversity metrics, including richness, Chao1, Shannon diversity (H), and Inverse Simpson, were not significantly different between sites or for transplanted fragments (Fig. S6).

Coral microbial communities had limited shared ASVs among samples. When an ASV was present in $>90 \%$ of all coral samples, it was considered to be a core member of the microbiome. Based on this definition, there were eight core ASVs, 6 of which belonged to the family Cyanobiaceae and 2 to the family Rhodobacteraceae. When examining Raffles and Kusu separately, the six core microbial members were present in each reef, except a reduction of one Cyanobiaceae at Raffles and an increase of three additional Cyanobiaceae
Fig. 2 Mean relative abundance of phyla in all resident, transplanted, and seawater samples. The seawater group includes seawater from Raffles and Kusu





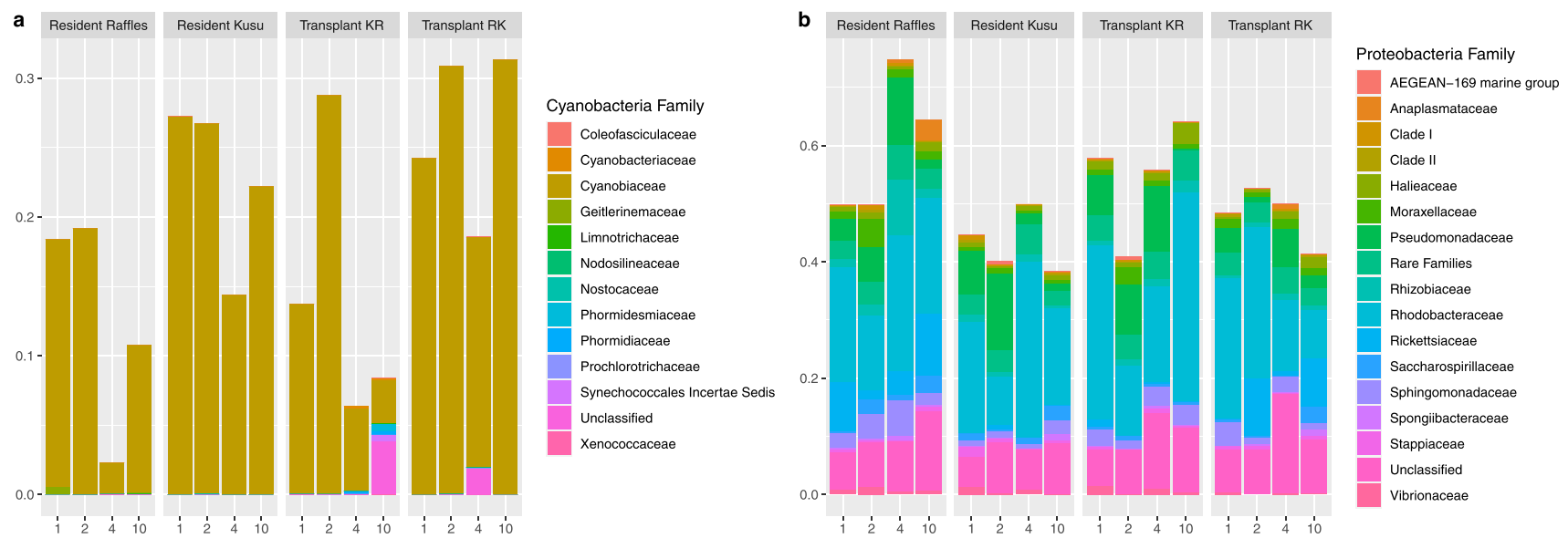

Fig. 3 Mean relative abundance at the family level of the two dominant taxa, $\mathbf{a}$ Cyanobacteria and $\mathbf{b}$ Proteobacteria, in the coral microbiomes for each sampling day following transplantation

at Kusu. If the core microbiome was redefined as ASVs present in $>70 \%$ of all coral samples, the number of core microbiome members shared across all samples at both reefs increased to 15, with additional ASVs including one Flavobacteriaceae, three Rhodobacteraceae, and three Cyanobiaceae. For Raffles, the core microbiome contained 16 members, when defining the core microbiome as presence in $70 \%$ of samples, and for Kusu, the number of ASVs within the core microbiome increased to 21. At Raffles, the 16 shared ASVs were made up of 8 Cyanobiaceae, 6 Rhodobacteraceae, 1 Flavobacteriaceae, and 1 from class Actinobacteria. At Kusu, the 21 shared ASVs were partitioned as 12 Cyanobiaceae, 5 Rhodobacteraceae, 2 Flavobacteriaceae, and 2 from class Actinobacteria.

Two-factor PERMANOVAs detected significant differences based on location (Raffles or Kusu) and time (days 1, $2,4,10)$ for each factor and interaction. Repeated analyses using origin (Raffles or Kusu) and time (days 1, 2, 4, 10) as factors also detected significant differences (Table S2). One day after transplantation, coral fragments remained differentiated by their source reef (origin); i.e., resident

Table 1 Pairwise PERMANOVA comparing the microbiome community structure of the coral fragments at 1,2, 4, and 10-days posttransplantation, first comparing the fragments based on the reef from which the corals originated (Origin) and secondly comparing the coral fragments based on the reef on which they were located on at the time of sampling (Location). The next comparisons are separated colonies remained similar to those that had been transplanted away from the source reef (Table 1). However, by the second day post-transplantation, the transplanted coral fragments were no longer similar to the resident colonies on their reef of origin but were instead more similar to their transplanted location. When assessing the response to transplantation within each reef separately, the microbiome shift happened more quickly for coral fragments transplanted from Kusu to Raffles (Table 1). There was no differentiation detected between the Resident Raffles and Transplant KR samples, but on day 1, there was a difference between the Resident Kusu and Transplant RK samples. When comparing homogeneity, or dispersion, among groups, PERMDISP analysis found increased dispersion for corals associated with Raffles, which led to a significant reduction in dispersion for corals that were transplanted from Raffles to Kusu (Table S3). Dispersion from the centroid was calculated for samples in the following groups: Resident Raffles (58.34 \pm 1.03$)$, Resident Kusu (55.17 \pm 0.99$)$, Transplant RK (53.12 \pm 0.94$)$, and Transplant KR $(58.13 \pm 0.83)$.

\begin{tabular}{|c|c|c|c|c|c|c|c|c|}
\hline & \multicolumn{2}{|l|}{ Origin } & \multicolumn{2}{|c|}{ Location } & \multicolumn{2}{|l|}{ Raffles } & \multicolumn{2}{|l|}{ Kusu } \\
\hline & $\mathrm{t}$ & $P$ & $\mathrm{t}$ & $P$ & $\mathrm{t}$ & $P$ & $\mathrm{t}$ & $P$ \\
\hline Day 1 & 1.2354 & 0.001 & 1.0994 & 0.034 & 1.1074 & 0.033 & 1.2237 & 0.004 \\
\hline Day 2 & 1.1106 & 0.091 & 1.1818 & 0.024 & 1.0150 & 0.328 & 1.1276 & 0.089 \\
\hline Day 4 & 1.0184 & 0.331 & 1.1891 & 0.001 & 1.0478 & 0.112 & 1.1015 & 0.086 \\
\hline Day 10 & 1.1393 & 0.046 & 1.3019 & 0.001 & 1.1789 & 0.218 & 0.9991 & 0.469 \\
\hline
\end{tabular}

within each respective reef, comparing the Resident Raffles fragments to the Transplant KR fragments (Raffles), followed by a comparison of the Resident Kusu fragments compared to the Transplant RK fragments (Kusu). The test statistic is included, and italics indicate significant differences based on corrected $\mathrm{P}$ values 
Resident coral microbiomes from each reef also changed during the 10-day experimental period (Table 2). At Raffles, there was a significant shift in the microbial community composition of the day 4 and day 10 resident fragments as compared to days 1 and 2 (Fig. 4a).

These results might be partially explained by the relative abundance of Cyanobacteria compared to Proteobacteria on day 4 (Fig. 3). For Kusu, the microbiome shift was apparent at day 2 and continued to day 4 . However, the day 10 samples were not distinct from the earlier sampling time points (Fig. 4b). There were no significant changes in dispersion within each site during the experiment (Raffles, $\mathrm{F}=2.5395$, $\mathrm{P}=0.144$; Kusu, $\mathrm{F}=1.8881, \mathrm{P}=0.556$ ); however, dispersion was higher for Resident Raffles and Transplant KR samples, compared with the Resident Kusu or Transplant RK samples (Table S3).

There were 27 Bacterial ASVs and 1 Archaeal ASV identified as highly significant $(P<0.01)$ based on the GLM in driving the differences among resident and transplanted corals and occurring with a mean relative abundance of $\geq 0.1 \%$

Table 2 Pairwise PERMANOVA comparing microbiome community structure of the Resident Raffles and Resident Kusu microbiomes within each reef over time. The test statistic is included, and italics indicate significant differences based on corrected $\mathrm{P}$ values

\begin{tabular}{llllll}
\hline & \multicolumn{2}{l}{ Raffles } & & \multicolumn{2}{l}{ Kusu } \\
\cline { 2 - 3 } & $\mathrm{t}$ & $P$ & & $\mathrm{t}$ & $P$ \\
\hline Day 0, day 1 & 1.0036 & 0.436 & & 1.1225 & 0.052 \\
Day 0, day 2 & 1.0035 & 0.428 & & 1.2789 & 0.010 \\
Day 0, day 4 & 1.2071 & 0.003 & & 1.2935 & 0.002 \\
Day 0, day 10 & 1.1671 & 0.015 & & 1.2537 & 0.029 \\
Day 1, day 2 & 0.9906 & 0.591 & 1.1854 & 0.006 \\
Day 1, day 4 & 1.1439 & 0.007 & 1.2577 & 0.002 \\
Day 1, day 10 & 1.1344 & 0.012 & 1.1118 & 0.303 \\
Day 2, day 4 & 1.0933 & 0.078 & & 1.1725 & 0.047 \\
Day 2, day 10 & 1.1081 & 0.094 & & 1.0781 & 0.325 \\
Day 4, day 10 & 1.0986 & 0.063 & 1.0960 & 0.349 \\
\hline
\end{tabular}

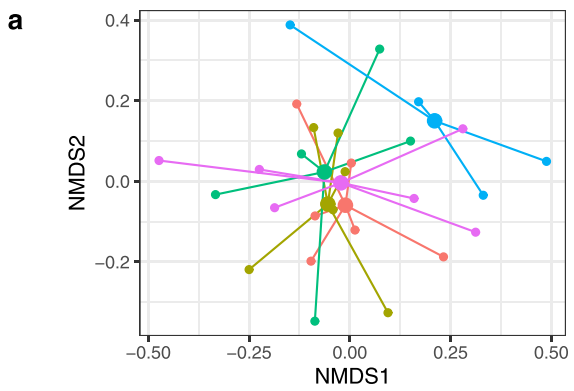

Fig. 4 nMDS plot of the a Resident Raffles and b Resident Kusu samples at each sampling day graphically represented as a spider plot connecting each sample with the daily group centroid. One sample in at least one of the four treatment groups (Table 3). Notably, Cyanobacteria was elevated at Kusu as compared to Raffles, and Cyanobacteria remained as the dominant taxa in the coral fragments that were transplanted from Kusu to Raffles. Corals from Kusu had elevated abundances of ASVs of Actinobacteriota, while those at Raffles had elevated Firmicutes, which were each acquired by fragments from the opposite reef following transplantation. Corals from Raffles and Kusu each had specific Bacteroidota ASVs that were retained in the transplanted fragments. Proteobacteria ASVs were primarily elevated among transplanted Raffles coral fragments; however, there was one ASV (ASV60) that was elevated in Kusu originating corals (Table 3). Two Verrucomicrobiota, closely related to the genus Simkania, were present in the Resident Kusu and Transplant KR fragments. The one significant Archaea identified by the GLM (Family Nitrosopumilaceae) had the lowest abundance in the Resident Raffles coral fragments.

Seawater nitrite, ammonia, phosphate, and silicate concentrations were not different between Raffles and Kusu during the 10-day period (Table S4). However, nitrate was significantly higher at Raffles $(0.9262 \pm 0.1994 \mu \mathrm{mol} / \mathrm{L})$ versus Kusu $(0.558 \pm 0.1563 \mu \mathrm{mol} / \mathrm{L}$; Fig. 5). Seawater temperature was not significantly different between reefs $\left(30.27 \pm 0.12{ }^{\circ} \mathrm{C}\right.$ at Raffles and $30.31 \pm 0.18{ }^{\circ} \mathrm{C}$ at Kusu; T-test: $\mathrm{t}=0.6580, \mathrm{df}=23.013, \mathrm{P}$ value $=0.517$ ).

\section{Discussion}

The coral microbiomes of $P$. acuta examined in this study were dynamic in response to both spatial and temporal changes. Coral microbiomes of both reefs exhibited temporal shifts during the experimental period. Coral microbiomes also responded rapidly, though differentially, to transplantation. Corals that were transplanted from Kusu (Transplant KR) were similar to the Resident Raffles corals within 1 day post-transplantation, while the colonies that were transplanted from Raffles (Transplant RK) were

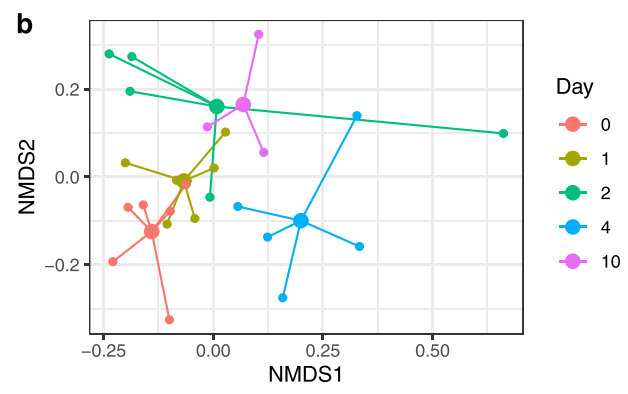

was removed on day 4 at Raffles to increase readability of the nMDS plot (see Fig. S7 for nMDS plot with sample included) 
Table 3 The percent abundance with standard deviation of the top $(>0.1 \%$ of total microbial community) ASVs identified as highly significant $(P<0.01)$ in driving the differences between resident and transplanted corals based on GLM

\begin{tabular}{|c|c|c|c|c|c|}
\hline ASV & Classification & Resident Kusu & Transplant KR & Resident Raffles & Transplant RK \\
\hline & Actinobacteriota & & & & \\
\hline 47 & Order PeM15 & $0.436 \pm 0.427$ & $0.049 \pm 0.102$ & $0.263 \pm 0.307$ & $0.692 \pm 0.526$ \\
\hline 52 & Order PeM16 & $0.448 \pm 0.452$ & $0.131 \pm 0.213$ & $0.233 \pm 0.360$ & $0.647 \pm 0.548$ \\
\hline \multirow[t]{2}{*}{159} & Class Actinobacteria & $0.086 \pm 0.144$ & $0.013 \pm 0.049$ & $0.098 \pm 0.275$ & $0.305 \pm 0.288$ \\
\hline & Bacteroidota & & & & \\
\hline 16 & Maritimimonas sp. & $1.447 \pm 1.710$ & $1.679 \pm 1.845$ & $0.097 \pm 0.196$ & $0.018 \pm 0.058$ \\
\hline 18 & Maritimimonas sp. & $1.287 \pm 1.401$ & $1.572 \pm 1.792$ & $0.129 \pm 0.258$ & $0.017 \pm 0.077$ \\
\hline 231 & Family Flavobacteriaceae & 0 & 0 & $0.115 \pm 0.233$ & $0.163 \pm 0.455$ \\
\hline 254 & Family Flavobacteriaceae & 0 & 0 & $0.118 \pm 0.254$ & $0.153 \pm 0.352$ \\
\hline \multirow[t]{2}{*}{430} & Family Flavobacteriaceae & 0 & 0 & $0.186 \pm 0.510$ & $0.016 \pm 0.066$ \\
\hline & Cyanobacteria & & & & \\
\hline 3 & Cyanobium PCC-6307 & $3.442 \pm 2.054$ & $1.228 \pm 1.645$ & $1.390 \pm 1.384$ & $4.216 \pm 3.207$ \\
\hline 4 & Cyanobium PCC-6307 & $3.824 \pm 2.559$ & $1.353 \pm 1.884$ & $1.493 \pm 1.589$ & $3.951 \pm 2.735$ \\
\hline 22 & Synechococcus CC9902 & $0.808 \pm 0.641$ & $0.341 \pm 0.527$ & $0.276 \pm 0.421$ & $0.835 \pm 0.506$ \\
\hline \multirow[t]{2}{*}{25} & Synechococcus CC9902 & $0.871 \pm 0.733$ & $0.374 \pm 0.488$ & $0.292 \pm 0.417$ & $0.777 \pm 0.532$ \\
\hline & Firmicutes & & & & \\
\hline 217 & Family Peptostreptococcaceae & 0 & $0.235 \pm 0.577$ & $0.178 \pm 0.418$ & $0.015 \pm 0.039$ \\
\hline 236 & Romboutsia sp. & 0 & $0.196 \pm 0.436$ & $0.213 \pm 0.415$ & $0.009 \pm 0.040$ \\
\hline 295 & Family Peptostreptococcaceae & 0 & $0.201 \pm 0.802$ & $0.063 \pm 0.137$ & 0 \\
\hline \multirow[t]{2}{*}{325} & Family Peptostreptococcaceae & 0 & $0.147 \pm 0.629$ & $0.081 \pm 0.186$ & 0 \\
\hline & Proteobacteria & & & & \\
\hline 23 & Family Rhodobacteraceae & $0.305 \pm 0.456$ & $0.078 \pm 0.137$ & $0.901 \pm 1.575$ & $1.508 \pm 3.262$ \\
\hline 24 & Family Rhodobacteraceae & $0.233 \pm 0.355$ & $0.084 \pm 0.137$ & $0.798 \pm 1.185$ & $1.336 \pm 2.450$ \\
\hline 60 & Family Rhodobacteraceae & $0.502 \pm 0.898$ & $0.434 \pm 0.571$ & $0.090 \pm 0.250$ & $0.054 \pm 0.151$ \\
\hline 81 & Erythrobacter sp. & $0.058 \pm 0.133$ & $0.358 \pm 0.539$ & $0.244 \pm 0.342$ & $0.342 \pm 0.360$ \\
\hline 151 & Class Gammaproteobacteria & 0 & $0.069 \pm 0.303$ & $0.191 \pm 0.361$ & $0.243 \pm 0.397$ \\
\hline 152 & Class Gammaproteobacteria & $0.003 \pm 0.014$ & $0.100 \pm 0.397$ & $0.190 \pm 0.309$ & $0.175 \pm 0.286$ \\
\hline 189 & Family Rhodobacteraceae & $0.064 \pm 0.147$ & 0 & $0.164 \pm 0.494$ & $0.118 \pm 0.253$ \\
\hline 191 & Family Rhodobacteraceae & $0.056 \pm 0.116$ & 0 & $0.174 \pm 0.426$ & $0.104 \pm 0.188$ \\
\hline \multirow[t]{2}{*}{230} & Family Halieaceae & 0 & $0.049 \pm 0.143$ & $0.135 \pm 0.487$ & $0.066 \pm 0.131$ \\
\hline & Verrucomicrobiota & & & & \\
\hline 165 & Simkania sp. & $0.286 \pm 0.724$ & $0.180 \pm 0.487$ & $0.003 \pm 0.011$ & $0.002 \pm 0.008$ \\
\hline \multirow[t]{2}{*}{180} & Simkania sp. & $0.230 \pm 0.646$ & $0.241 \pm 0.675$ & 0 & 0 \\
\hline & Crenarchaeota & & & & \\
\hline 113 & Family Nitrosopumilaceae & $0.200 \pm 0.302$ & $0.150 \pm 0.293$ & $0.015 \pm 0.049$ & $0.352 \pm 0.905$ \\
\hline
\end{tabular}

similar to the Resident Kusu colonies within 2 days posttransplantation. Coral samples from Raffles, as well as the Transplant KR fragments, displayed greater dispersion, or increased beta diversity, than fragments transplanted to Kusu, which may have contributed to the different rates of microbiome response to transplantation. Corals originating from Raffles may have taken longer to become similar to the Resident Kusu corals, because the Raffles corals were comprised of more divergent microbial communities. Conversely, the transition in microbiomes of corals that were transplanted from Kusu to Raffles may have happened more quickly, because the samples from Kusu were a less divergent community that became more dispersed.
Corals from both locations had microbiomes dominated by phylum Proteobacteria, followed by phylum Cyanobacteria. These results are consistent with a previous study, which characterized $P$. acuta from Kusu as having a high abundance of both Proteobacteria and Cyanobacteria [13]. However, a similarly high abundance of Cyanobacteria was not previously observed in $P$. acuta from Raffles. The high abundance of Cyanobacteria found in corals from Raffles in this study could be linked to the elevated nitrate concentrations observed there, as Cyanobacteria can process nitrate and has been positively correlated with nitrate concentrations [39]. Elevated Cyanobacteria abundance has been associated with coral reef ecosystem degradation, and 

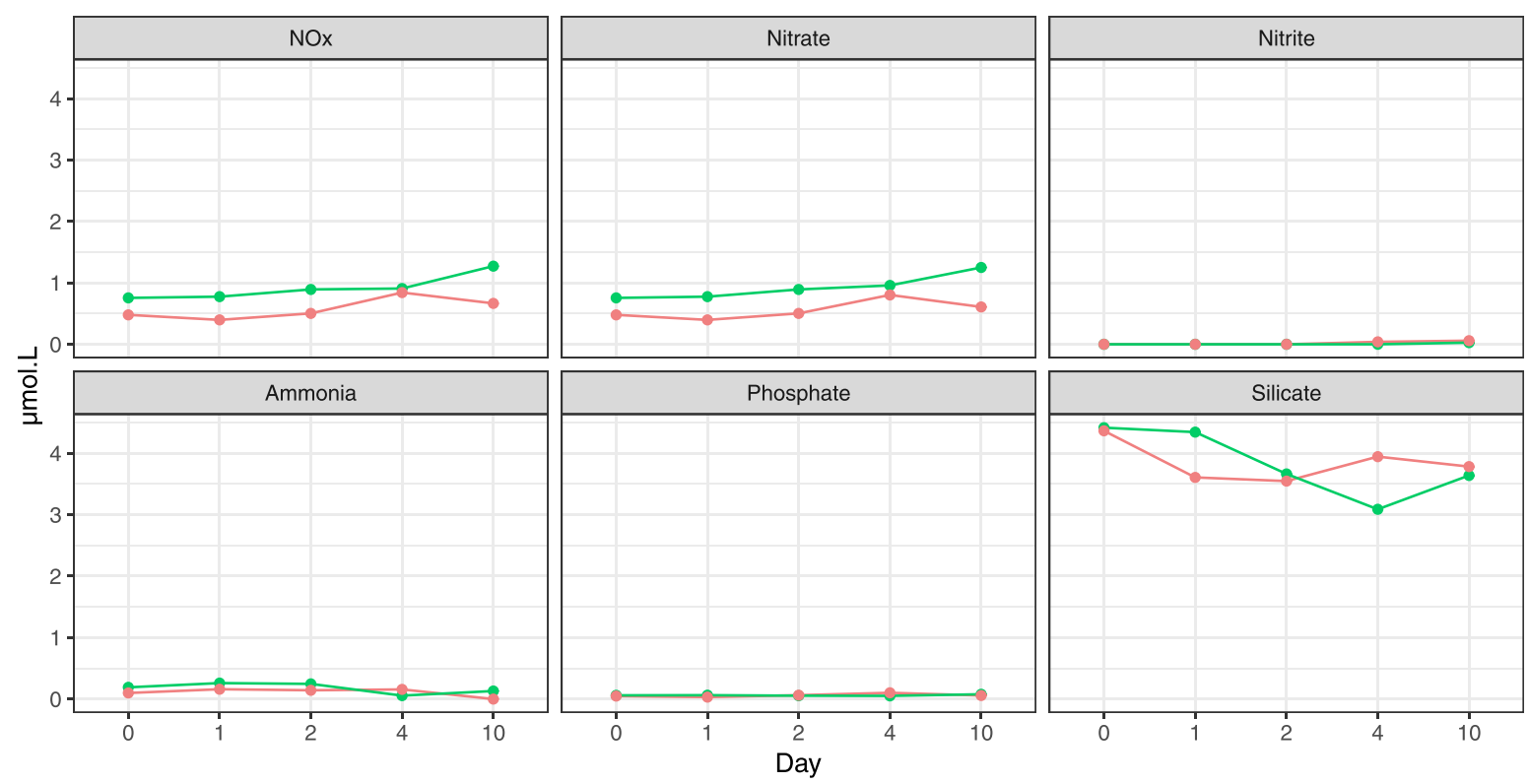

Reef

$\rightarrow$ Kusu

$\rightarrow$ Raffles

Fig. 5 Seawater nutrient concentrations at Raffles and Kusu during the experiment

some Cyanobacteria can be a precursor to coral disease [40, 41]. However, none of the abundant Cyanobacteria found in this study were previously identified as pathogenic to corals. Cyanobacteria were also found in the seawater from both Raffles and Kusu, so it is possible that some Cyanobacteria identified from the coral samples were surface-associated bacteria and not incorporated into the coral microbiome, as the mucus layer can more readily incorporate environmental bacteria [11, 42]. While samples examined in this study were composed primarily of coral tissue, some mucus was likely included. However, given that Cyanobacteria have been previously reported in the microbiome of $P$. acuta tissue from Kusu, at least some Cyanobacteria may be persistent associates of the coral microbiome.

Coral transplantation can facilitate the colonization of disease pathogens in corals [43], although there was no apparent increase in potentially pathogenic bacteria in the transplanted fragments. Two Verrucomicrobiota, most closely matching the genus Simkania, were present in the Resident Kusu fragments and retained by the Transplanted KR fragments; however, the two bacteria were not acquired by corals transplanted from Raffles to Kusu. The genus Simkania currently contains one species, S. negevensis [44], which has been implicated as a human pathogen [45]. Both strains of Simkania spp. had 98\% and 97.8\% identity, respectively, to $S$. negevensis, suggesting they represent a closely related yet undescribed Simkania species. Given the potential association of these bacteria with human infections, it is notable that they only occurred in corals originating from Kusu, the reef located closer to the mainland of Singapore.
In addition to the shift induced by transplantation, we observed natural shifts in the resident coral microbiomes over the 10-day experiment. While there is evidence of coral microbiomes responding quickly to stress $[15,46]$, there is limited information about the dynamic nature of coral microbiomes from day to day. This shift in microbiome community structure could be a response to fragmentation of the resident colonies, which were fragmented similar to the transplanted samples. However, there was no change in beta diversity of the resident colonies within each reef over time, suggesting that the microbiome shifts reflect natural fluctuations in the coral microbial communities at each site. There was a slight increase in $\mathrm{NO}_{\mathrm{x}}$ during the study, which could have contributed to the temporal changes in coral microbiomes. In particular, the differences in nitrate concentration detected between the reefs could contribute to site-specific differences, as nitrogen concentrations remained elevated at Raffles compared to Kusu for the duration of the experiment. In contrast, no other water quality parameters measured in this study, including temperature or nutrient concentrations, can fully explain the temporal microbiome changes observed. Future studies should monitor a broader range of environmental parameters.

Of the two reefs compared in this study, Kusu is generally considered to experience greater anthropogenic impacts than Raffles, due to its proximity to the mainland of Singapore ( $4 \mathrm{~km}$ from mainland Singapore versus $\sim 13 \mathrm{~km}$, respectively). Previous monitoring reported greater water movement at Raffles as compared to Kusu, with no significant differences observed between sites for sedimentation rate, temperature, or nutrient concentrations 
[47]. Wainwright et al. [13] attributed differences in coral microbiomes between Raffles and Kusu to the strong directionality of water movement from east to west differentially affecting the windward and leeward sides of Singapore's Southern Islands, particularly during the Northeast Monsoon [31]. The current study was conducted during the inter-monsoon period with light winds and relatively calm seas, which may explain why the coral microbiomes between the two reefs were not as divergent as in previous studies $[13,30]$. The mean seawater temperature of approximately $30{ }^{\circ} \mathrm{C}$ recorded at each reef and the nutrient concentrations are consistent with expectation for Singaporean waters $[31,48]$. However, the elevated nitrogen concentrations around Raffles may have contributed to the higher beta diversity observed for corals within that site $[24,49]$, if they represented anomalous nitrogen loading in the system. While only a small fraction of water quality parameters characterizing the two reefs were accounted for in this study, even in urbanized reef communities, environmental variables are not always explanatory of microbiome composition [50].

Corals in Singapore are adapted to an environment of high disturbance, which is often associated with an increased beta diversity of the microbiome $[16,17$, 22-24]. In this study, the microbiome of P. acuta readily shifted, but no dysbiosis, or shift to disease state, was observed. These findings are consistent with $P$. acuta from the Great Barrier Reef, in which the microbiome changed in composition in response to a thermal stress event [19], although the differences observed on the Great Barrier Reef were not as pronounced as those reported here. The results of this study support the hypothesis that the coral microbiome is highly dynamic, readily shifting in response to changes in the environment, with only a small group of core microbial members. The dynamic microbiome of $P$. acuta in Singapore may be an adaptation to the environmental fluctuations consistent with the intense anthropogenic impacts experienced on Singapore's urban reefs. Additional studies are needed to elucidate the exact role of individual microbial members on coral health and to determine whether the microbiome variations have a net negative or positive effect on long-term survival. Thus, corals from Singapore represent a model of resilience and therefore understanding how their microbiomes have adapted to the environment may yield clues to their persistence on these heavily impacted reefs.

Supplementary Information The online version contains supplementary material available at https://doi.org/10.1007/s00248-021-01793-w.

Acknowledgements We would like to thank Ho Xin Yi and Aaron Loh An Rong for their contributions to the field work and sample processing in the laboratory and Scott Rice for the contributions to manuscript editing. We also thank Patrick Martin of the Asian School of the
Environment at Nanyang Technological University for processing the seawater nutrient samples. This research was carried out under the permit (NP/RP16-156-2c) granted by the Singapore National Parks Board.

Funding This project was funded by the Marine Research and Development Program (MSRDP-03) from the Singapore National Research Foundation and the Ministry of Education Singapore under its Research Centre of Excellence Program to the Singapore Centre for Environmental Life Sciences Engineering, Nanyang Technological University.

Data Availability Raw sequencing reads were uploaded to the NCBI Sequence Read Archive (SRA) under BioProject PRJNA667314.

\section{Declarations}

Conflict of Interest The authors declare no competing interests.

Open Access This article is licensed under a Creative Commons Attribution 4.0 International License, which permits use, sharing, adaptation, distribution and reproduction in any medium or format, as long as you give appropriate credit to the original author(s) and the source, provide a link to the Creative Commons licence, and indicate if changes were made. The images or other third party material in this article are included in the article's Creative Commons licence, unless indicated otherwise in a credit line to the material. If material is not included in the article's Creative Commons licence and your intended use is not permitted by statutory regulation or exceeds the permitted use, you will need to obtain permission directly from the copyright holder. To view a copy of this licence, visit http://creativecommons.org/licenses/by/4.0/.

\section{References}

1. Pandolfi JM, Bradbury RH, Sala E, Hughes TP, Bjorndal KA, Cooke RG et al (2003) Global trajectories of the long-term decline of coral reef ecosystems. Science 301:955-958

2. Norström AV, Nyström M, Jouffray JB, Folke C, Graham NAJ, Moberg $\mathrm{F}$ et al (2016) Guiding coral reef futures in the Anthropocene. Front Ecol Environ 14:490-498

3. Bourne DG, Morrow KM, Webster NS (2016) Insights into the coral microbiome: underpinning the health and resilience of reef ecosystems. Annu Rev Microbiol 70:317-340

4. Apprill AM, Gates RD (2007) Recognizing diversity in coral symbiotic dinoflagellate communities. Mol Ecol 16:1127-1134

5. Suggett DJ, Warner ME, Leggat W (2017) Symbiotic dinoflagellate functional diversity mediates coral survival under ecological crisis. Trends Ecol Evol 32:735-745

6. Blackall LL, Wilson B, van Oppen MJH (2015) Coralthe world's most diverse symbiotic ecosystem. Mol Ecol 24:5330-5347

7. Ainsworth TD, Krause L, Bridge T, Torda G, Raina JB, Zakrzewski $M$ et al (2015) The coral core microbiome identifies rare bacterial taxa as ubiquitous endosymbionts. ISME J 9:2261-2274

8. Hernandez-Agreda A, Leggat W, Bongaerts P, Herrera C, Ainsworth TD (2018) Rethinking the coral microbiome: simplicity exists within a diverse microbial biosphere. mBio 9:e00812-18

9. Peixoto RS, Rosado PM, Leite DCA, Rosado AS, Bourne DG (2017) Beneficial Microorganisms for Corals (BMC): Proposed mechanisms for coral health and resilience. Front Microbiol 8:341

10. Webster NS, Reusch TBH (2017) Microbial contributions to the persistence of coral reefs. ISME J 11:2167-2174 
11. Pollock FJ, McMinds R, Smith S, Bourne DG, Willis BL, Medina $\mathrm{M}$ et al (2018) Coral-associated bacteria demonstrate phylosymbiosis and cophylogeny. Nat Commun 9:4921

12. Speare L, Davies SW, Balmonte JP, Baumann J, Castillo KD (2020) Patterns of environmental variability influence coralassociated bacterial and algal communities on the Mesoamerican Barrier Reef. Mol Ecol 29:2334-2348

13. Wainwright BJ, Afiq-Rosli L, Zahn GL, Huang D (2019) Characterisation of coral-associated bacterial communities in an urbanised marine environment shows strong divergence over small spatial scales. Coral Reefs 38:1097-1106

14. Koren O, Rosenberg E (2006) Bacteria associated with mucus and tissues of the coral Oculina patagonica in summer and winter. Appl Environ Microbiol 72:5254-5259

15. Ziegler M, Seneca F, Yum L, Palumbi S, Voolstra C (2017) Bacterial community dynamics are linked to patterns of coral heat tolerance. Nat Commun 8:14213

16. Leite DCA, Salles JF, Calderon EN, Castro CB, Bianchini A, Marques JA et al (2018) Coral bacterial-core abundance and network complexity as proxies for anthropogenic pollution. Front Microbiol 9:833

17. Claar DC, McDevitt-Irwin JM, Garren M, Vega-Thurber R, Gates RD, Baum JK (2020) Increased diversity and concordant shifts in community structure of coral-associated Symbiodiniaceae and bacteria subjected to chronic human disturbance. Mol Ecol 29:2477-2491

18. Grottoli AG, Dalcin Martins P, Wilkins MJ, Johnston MD, Warner ME, Cai W-J, Melman TF, Hoadley KD, Pettay DT, Levas S, Schoepf V (2018) Coral physiology and microbiome dynamics under combined warming and ocean acidification. PLoS One 13:e0191156

19. Epstein HE, Torda G, van Oppen MJH (2019) Relative stability of the Pocillopora acuta microbiome throughout a thermal stress event. Coral Reefs 38:373-386

20. Hadaidi G, Rothig T, Yum L, Ziegler M, Arif C, Roder C et al (2017) Stable mucus-associated bacterial communities in bleached and healthy corals of Porites lobata from the Arabian Seas. Sci Rep 7:45362

21. Pogoreutz C, Rädecker N, Cárdenas A, Gärdes A, Wild C, Voolstra CR (2018) Dominance of Endozoicomonas bacteria throughout coral bleaching and mortality suggests structural inflexibility of the Pocillopora verrucosa microbiome. Ecol Evol 8:2240-2252

22. McDevitt-Irwin JM, Baum JK, Garren M, Vega Thurber RL (2017) Responses of coral-associated bacterial communities to local and global stressors. Front Mar Sci 4:262

23. Zaneveld J, McMinds R, Vega Thurber R (2017) Stress and stability: applying the Anna Karenina principle to animal microbiomes. Nat Microbiol 2:17121

24. Wang L, Shantz AA, Payet JP, Sharpton TJ, Foster A, Burkepile DE, Vega Thurber R (2018) Corals and their microbiomes are differentially affected by exposure to elevated nutrients and a natural thermal anomaly. Front Mar Sci 5:101

25. Bauman AG, Guest JR, Dunshea G, Low J, Todd PA, Steinberg PD (2015) Coral settlement on a highly disturbed equatorial reef system. PLoS One 10:e0127874

26. Guest JR, Tun K, Low J, Vergés A, Marzinelli EM, Campbell AH et al (2016) 27 years of benthic and coral community dynamics on turbid, highly urbanised reefs off Singapore. Sci Rep 6:36260

27. Heery EC, Hoeksema BW, Browne NK, Reimer JD, Ang PO, Huang D et al (2018) Urban coral reefs: degradation and resilience of hard coral assemblages in coastal cities of East and Southeast Asia. Mar Pollut Bull 135:654-681
28. Chou LM, Huang D, Tan KS, Toh TC, Goh BPL, Tun K (2019) Singapore. In: Sheppard CRC (ed) World seas: an environmental evaluation, vol II. the Indian Ocean to the Pacific. Academic Press, London, pp 539-558

29. Poquita-Du RC, Quek Z, Jain SS, Schmidt-Roach S, Tun K, Heery EC et al (2019) Last species standing: loss of Pocilloporidae corals associated with coastal urbanization in a tropical city state. Mar Biodiv 49:1727-1741

30. Fong J, Deignan LK, Bauman AG, Steinberg PD, McDougald D, Todd PA (2020) Contact- and water-mediated effects of macroalgae on the physiology and microbiome of three Indo-Pacific coral species. Front Mar Sci 6:831

31. Sin TM, Ang HW, Buurman J, Lee AC, Leong YL, Ooi SK et al (2016) The urban marine environment of Singapore. Reg Stud Mar Sci 8:331-339

32. Caporaso JG, Lauber CL, Walters WA, Berg-Lyons D, Lozupone CA, Turnbaugh PJ, Fierer N, Knight R (2011) Global patterns of $16 \mathrm{~S}$ rRNA diversity at a depth of millions of sequences per sample. Proc Natl Acad Sci 108:4516-4522

33. Davis NM, Proctor D, Holmes SP, Relman DA, Callahan BJ (2018) Simple statistical identification and removal of contaminant sequences in marker-gene and metagenomics data. Microbiome 6:226

34. Murali A, Bhargava A, Wright ES (2018) IDTAXA: a novel approach for accurate taxonomic classification of microbiome sequences. Microbiome 6:140

35. Morgan M (2020) DirichletMultinomial: Dirichlet-multinomial mixture model machine learning for microbiome data. $\mathrm{R}$ package version 1.30 .0

36. Holmes I, Harris K, Quince C (2012) Dirichlet multinomial mixtures: generative models for microbial metagenomics. PLoS One 7:e03126

37. Weiss S, Xu ZZ, Peddada S, Amir A, Bittinger K, Gonzalez A et al (2017) Normalization and microbial differential abundance strategies depend upon data characteristics. Microbiome 5:27

38. Narum SR (2006) Beyond Bonferroni: less conservative analyses for conservation genetics. Conserv Genet 7:783-787

39. Marchioro GM, Glasl B, Engelen AH, Serrão EA, Bourne DG, Webster NS, Frade PR (2020) Microbiome dynamics in the tissue and mucus of acroporid corals differ in relation to host and environmental parameters. PeerJ 8:e9644

40. Sussman M, Bourne DG, Willis BL (2006) A single cyanobacterial ribotype is associated with both red and black bands on diseased corals from Palau. Dis Aquat Org 69:111-118

41. Frias-Lopez J, Bonheyo GT, Jin Q, Fouke BW (2016) Cyanobacteria associated with coral black band disease in Caribbean and Indo-Pacific reefs. Appl Environ Micro 69:2409-2413

42. Glasl B, Herndl GJ, Frade PR (2016) The microbiome of coral surface mucus has a key role in mediating holobiont health and survival upon disturbance. ISME J 10:2280-2292

43. Casey JM, Connolly SR, Ainsworth TD (2015) Coral transplantation triggers shift in microbiome and promotion of coral disease associated potential pathogens. Sci Rep 5:11903

44. Kahane S, Gonen R, Sayada C, Elion J, Friedman MG (1993) Description and partial characterization of a new chlamydia-like microorganism. FEMS Microbiol Lett 109:329-333

45. Vouga M, Baud D, Greub G (2017) Simkania negevensis may produce long-lasting infections in human pneumocytes and endometrial cells. Pathog Dis 75:ftw115

46. Sweet MJ, Brown BE, Dunne RP, Singleton I, Bulling M (2017) Evidence for rapid, tide-related shifts in the microbiome of the coral Coelastrea aspera. Coral Reefs 36:815-828 
47. Ng CSL, Lim JX, Sam SQ, Kikuzawa YP, Toh TC, Wee TW et al (2019) Variability in skeletal bulk densities of common hard corals in Southeast Asia. Coral Reefs 38:1133-1143

48. Chénard C, Wijaya W, Vaulot D, dos Santos AL, Martin P, Kaur A, Lauro FM (2019) Temporal and spatial dynamics of Bacteria, Archaea and protists in equatorial coastal waters. Sci Rep 9:16390

49. van de Water JAJM, Melkonian R, Voolstra CR, Junca H, Beraud E, Allemand D, Ferrier-Pagès C (2017) Comparative assessment of Mediterranean Gorgonian-associated microbial communities reveals conserved core and locally variant bacteria. Microb Ecol 73:466-478

50. Röthig T, Bravo H, Corley A, Prigge TL, Chung A, Yu V et al (2020) Environmental flexibility in Oulastrea crispata in a highly urbanised environment: a microbial perspective. Coral Reefs 39:649-662 